Vol. 11 (1): 103-112 (2021)

\title{
REGIONAL PRIORITIES FOR THE DESIGN OF SUSTAINABLE ARCHITECTURE BY LEED METHOD IN TEHRAN
}

\author{
Seyed Mohammadyaser Mousavi Boora ${ }^{1 *}$, Mojtaba Karimnezhad ${ }^{2}$ \\ ${ }^{1 *}$ Eastern Mediterranean University, Faculty of Architecture, Department of Interior Architecture, Famagusta, \\ North Cyprus; \\ ${ }^{2}$ Eastern Mediterranean University, Faculty of Architecture, Department of Architecture, Famagusta, \\ North Cyprus;
}

*Corresponding Author Seyed Mohammadyaser Mousavi Boora, e-mail: boora@aftermail.ir;

Received November 2020; Accepted December 2020; Published January 2021;

DOI: https://doi.org/10.31407/ijees11.114

\begin{abstract}
In today's world, every building must be designed to minimize the need for fossil fuels, energy efficiency in today's buildings is the first goal to improve energy consumption, high energy costs and severe environmental impacts, the demand for building design Increased sustainability, many developed countries now use standards to increase the efficiency of buildings that are more compatible with our environment. In a way, it has become competitive with other buildings to offer to the consumer market. The purpose of this study is to achieve a strategic priority classification responsive to Tehran's climate that can be the basis for measuring the success of sustainable projects and such designs, so based on areas that have this advantage; it was found that regional priority credits are determined according to its sub-criteria. It should be noted that this research is applied in terms of purpose, in terms of approach is survey and exploratory study. The main tool of data collection in this study was a questionnaire that was designed for different purposes and after obtaining approval was distributed among 86 architects and civil engineers. After distributing and collecting data, performing the necessary analysis through SPSS, Excel and Matlab software was on the agenda. Finally, the results of the study led to the identification of 10 indicators in the form of 5 groups and their final weight was calculated.
\end{abstract}

Keywords: Sustainable Architecture, LEED, regional priority, credit, clean energy 